\title{
Impact of Neuropathic Pain at the Population Level
}

\author{
Ana Shirley Maranhao Vieira, ${ }^{\mathrm{a}, \mathrm{d}}$, Abrahao Fontes Baptista ${ }^{\mathrm{b}}$, Livia Mendes ${ }^{\mathrm{a}}$, \\ Kamilla Soares Silva a, Sharize Cristine de Araujo Gois ${ }^{\mathrm{a}}$, \\ Flavia Manoela de Almeida Lima ${ }^{a}$, Israel Souza ${ }^{c}$, Katia Nunes Sa
}

\begin{abstract}
Background: One of the chief complaints of individuals who frequent the Family Health Units is chronic pain which, in Salvador, affects over $40 \%$ of the population. However, little is known about the type of pain and its impact on quality of life (QoL) at population level. The aim of the study is to evaluate the impact of neuropathic pain on QoL in a community.
\end{abstract}

Methods: A descriptive cross-sectional study was conducted from March to October 2012, in a Family Health Unit, Salvador, Bahia, Brazil. The DN-4 (type of pain), body map (location), VAS (intensity) and SF-36 (QoL) instruments were applied. The Chi-square (univariate analysis) and logistic regression (multivariate) tests were used, with IC $95 \%$ and $\mathrm{P}<0.05$.

Results: In a sample of 191 individuals with chronic pain, predominantly women $(86.4 \%)$, single $(48.7 \%)$, nonwhite $(93.2 \%)$, low educational (46.6\%) and low economic (100\%) level. The most affected locations of the body were knees, lumbar region and head. In $60.2 \%$ of interviewees, neuropathic pain, of high intensity (VAS $=7.09 \pm 3.0)$ predominated, with duration of $8.53 \pm 8.8$ years and mean QoL was reduced in $47.13 \%$.

Conclusions: Intense pain in the dorsal region and type of neuropathy are independent predictors for greater compromise of QoL.

Manuscript accepted for publication November 27, 2013

${ }^{a}$ Escola Bahiana de Medicina e Saude Publica, Salvador, Bahia, Brazil

${ }^{\mathrm{b}}$ Universidade Federal da Bahia, Salvador, Bahia, Brazil

${ }^{\mathrm{c}}$ Instituto Federal de Educacao, Ciencia e Tecnologia do Rio de Janeiro, Rio de Janeiro, Brazil

${ }^{\mathrm{d} C}$ Corresponding author: Ana Shirley Maranhao Vieira, Rua do Albatroz, 169, Apto. 404, Imbui, Salvador, Bahia, Brazil.

Email: asmvieira@bahiana.edu.br

doi: http://dx.doi.org/10.14740/jocmr1675w
Keywords: Pain; Chronic pain; Population; Quality of life; Neuropathic pain

\section{Introduction}

Pain affects different aspects of human beings and its interpretation varies from one cultural and socioeconomic condition to another. It is a multifactorial phenomenon that involves everything from tissue damage to environmental aspects $[1,2]$. According to IASP (International Association for the Study of Pain), pain is an unpleasant sensory and emotional experience associated with real or potential lesions of tissues, or described in their terms [3]. When the pain lasts for longer than 6 months, it is classified as chronic. It compromises the quality of life $(\mathrm{QoL})$, making the individual unable to perform activities [1].

Chronic pain has been shown to be associated with the symptoms of neuropathic pain and this association affects QoL [4]. Neuropathic pain is defined as a result of injury nerve, and is regarded as a complex syndrome with organic mechanical yet fully understood [5].

In spite of being a public health problem in Brazil, little is known about chronic pain, especially at the population level [6]. It is essential to define the type of pain, intensity, site affected and its impact on the QoL.

The Family Health Units (FHUs) provide follow-up of persons with chronic diseases [7]. One of the most common complaints found in the communities is pain, which in Salvador, affects $41.4 \%$ of the population [8]. The Basic Health Care professionals are responsible for a person's first contact with the health system. They may, however, contribute to tracing the causal factors of chronic pain and interfere in control of the problem [9].

The term QoL related to health has been implicated by the aspects most directly associated with the diseases, by including the perception of persons who suffer from the problem [10-12]. Different instruments are used for evaluating QoL and health status [11, 13]. Therefore, the aim of this study was to evaluate the impact of neuropathic pain on the QoL in a community. 
Table 1. Sociodemographic Characterization of the Sample Population of a Registered Health Unit, Salvador, Bahia, Brazil

\begin{tabular}{|c|c|c|c|}
\hline Variables & & $\mathbf{n}$ & $\%$ \\
\hline \multirow[t]{2}{*}{ Sex } & Female & 165 & 86.4 \\
\hline & Male & 26 & 13.6 \\
\hline \multirow[t]{3}{*}{ Age } & $20-30$ & 23 & 12.0 \\
\hline & $31-60$ & 144 & 75.4 \\
\hline & $61-90$ & 24 & 12.6 \\
\hline \multirow[t]{3}{*}{ Marital status } & Single & 93 & 48.7 \\
\hline & Married & 71 & 37.2 \\
\hline & Others & 27 & 14.1 \\
\hline \multirow[t]{2}{*}{ Skin color } & Nonwhite & 178 & 93.2 \\
\hline & White & 13 & 6.8 \\
\hline \multirow[t]{3}{*}{ Smoking } & No & 115 & 60.5 \\
\hline & Yes & 29 & 15.3 \\
\hline & Ex-smoker & 46 & 24.2 \\
\hline \multirow{3}{*}{$\begin{array}{l}\text { Consumption of } \\
\text { alcoholic beverages }\end{array}$} & Non-consumer & 114 & 59.7 \\
\hline & Moderate & 72 & 37.7 \\
\hline & Excessive & 5 & 2.6 \\
\hline
\end{tabular}

\section{Methods}

A descriptive, cross-sectional population-based study was conducted in the FHU Zulmira Barros, Salvador, Bahia, Brazil. The multiprofessional team that acts in the Unit serves the communities Recanto Feliz and Paraiso Azul. It comprises a population of 2,357 inhabitants, according to the Basic Care Information System/2011.

Individuals registered with the FHU, 20 years of age or older, who had been in pain for a period equal to or longer than 6 months, were selected. The criteria for exclusion from data collection were pregnant women, and individuals who were cognitively incapable of responding to the questionnaires.

After applying the inclusion and exclusion criteria, the population was reduced to 1,550 persons. When applying a prevalence of $41.4 \%$ of chronic pain in Salvador [8], the number of affected persons was estimated at 620 individuals. Calculating the sample according to WINPEPI (Package of Statistical Programs for Epidemiologists for Windows), with an interval of confidence of $95 \%$ and acceptable differ- ence of $7 \%$, the proposal was to conduct the study with 190 individuals.

The participants were approached in the FHU, or by indication and in the company of the community health agents, visited in their homes and were invited to participate in an interview with the application of questionnaires to characterize pain. All the participants signed the term of free and informed consent.

The instruments used were as follows: questionnaires on sociodemographic and clinical aspects, and versions validated for Brazilian Portuguese of DN-4 (questionnaire for diagnosis of neuropathic pain) [14] and of SF-36 (Short Form 36) [13]. The body map was also used to identify the sites affected, and the visual pain scale to measure the intensity.

The period for conducting the field research occurred during the months from March to October, 2012. In order to guarantee the quality of data, the same instruments were re-applied in $10 \%$ of the studied population, to evaluate the inter-examiner agreement, and after one month, the instrument was re-applied in the same proportion of the studied population to guarantee intra-examiner agreement. 


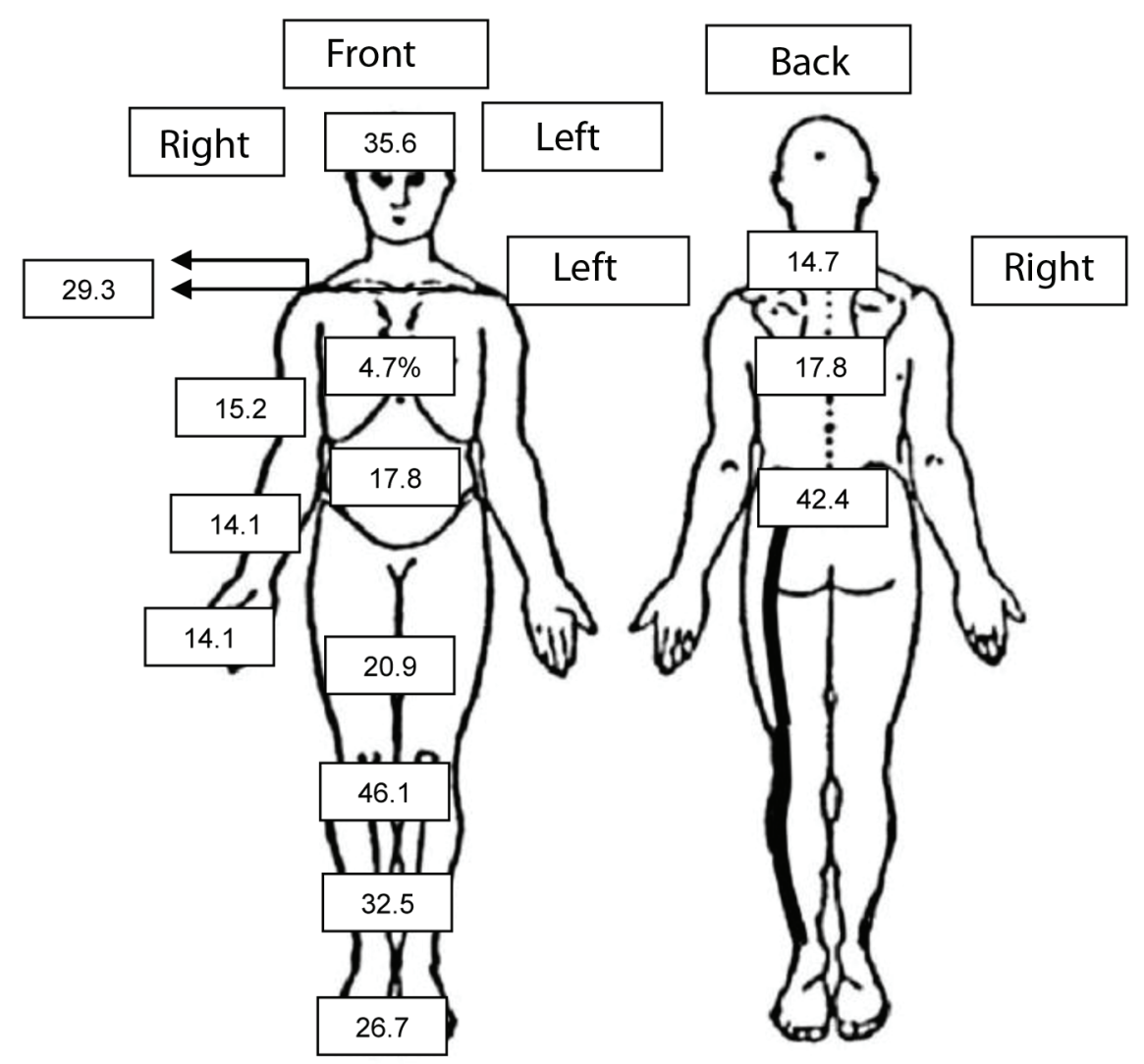

Figure 1. Sites in the body affected by pain in the population sample of a registered health unit, Salvador, Bahia, Brazil.

\section{Statistical analyses}

The independent variables were: sex, age, marital status, skin color, alcoholism, smoking, time, intensity, site and type of pain. The dependent variable was the impact on QoL of those affected by pain. The data obtained were tabled and analyzed in the Program SPSS for Windows version 17.0. For the inferences, the Chi-square test was used in the univariate analysis for nominal variables. To verify the independent impact of the studied variables on the type of pain and QoL, the logistic regression technique was used, which allows the odds ratio (OR) to be estimated from the medians, indicating which characteristic is implicated in greater or lower chance of leading to an "uncompromised" or "compromised" QoL. Initially, univariate logistic regression models were adjusted for all the explanatory variables, considering a level of significance of $10 \%(\mathrm{P}<0.10)$ for entry into the model.

The variables selected at this stage were introduced into a single model, and afterwards, the automatic stepwise backward selection procedure was performed, so that only those significant at $5 \%$ or those that contributed to better adjustment of the model remained in the model. Adjustment of the models was evaluated by the Hosmer-Lemeshow test.

In the specific case of the dimensions QoL measured by SF-36, these were dichotomized based on the median for use in the logistic regression. Individuals with a score equal to or below the median were classified has having a "compromised QoL", and those with a score higher than the median, as having an "uncompromised QoL".

This study was approved by the Ethics Committee of the Bahian School of Medicine and Public Health, and authorized by the Municipal Secretary of Health of Salvador.

\section{Results}

The sample of this study was composed of 191 individuals. The mean age of the participants was $46.2 \pm 13.8$ years.

With reference to sociodemographic characterization, the study population was composed of $86.4 \%$ of the female sex, the majority being single, self-reported as being of nonwhite color. The majority of the sample consisted of nonsmokers and those who did not consume alcohol (Table 1).

As regards the clinical characterization of pain, the individuals reported feeling pain for at least 5 years, and 25.7\% reported intense pain. The sites in the body most affected by the presence of pain are shown in Figure 1. By means of DN-4, $60.2 \%$ of the subjects were classified as having neuropathic pain.

The intensity of pain in these individuals showed a mean 
Table 2. Impact of Pain on the QoL of the Population Sample of a Registered Health Unit, Salvador, Bahia, Brazil

\begin{tabular}{llll}
\hline QoL (SF-36 in \%) & Median & $\begin{array}{l}\text { Compromised QoL } \\
\mathbf{n}(\%)\end{array}$ & $\begin{array}{l}\text { Uncompromised QoL } \\
\mathbf{n}(\%)\end{array}$ \\
\hline Functional capacity & 65.00 & $96(50.26)$ & $95(49.74)$ \\
Physical aspect & 50.00 & $106(55.50)$ & $85(44.50)$ \\
Pain & 45.00 & $97(50.79)$ & $94(49.21)$ \\
General state of health & 57.00 & $104(54.45)$ & $87(45.55)$ \\
Vitality & 60.00 & $98(51.31)$ & $93(48.69)$ \\
Social aspect & 62.50 & $112(58.64)$ & $79(41.36)$ \\
Emotional aspect & 33.33 & $97(50.79)$ & $94(49.21)$ \\
Mental health & 64.00 & $97(50.79)$ & $94(49.21)$ \\
Total score & 52.87 & $97(50.79)$ & $94(49.21)$ \\
\hline
\end{tabular}

of $7.09 \pm 3.0$, with mean duration of $8.53 \pm 8.8$ years. The general state of health was considered good by $64.4 \%$ of the sample.

The QoL was reduced in $47.13 \%$, and Table 2 lists the most compromised domains.

As there was higher prevalence of neuropathic pain, the option was taken to consider it as outcome for the regression model. For this, multiple logistic regression was performed, aiming to assess the impact of a single variable in "neuropathic pain", in addition to confidence intervals of $95 \%$.

When analyzing each variable alone, it was noted that at a level of significance lower than or equal to $10 \%$, only the presences of pain in the shoulders, in the dorsal region, in the arms, in the hands, in the thighs, in the knees, in the legs and in feet were significant, always indicating that having pain in these locations increased the individual's chance of being diagnosed with "neuropathic pain" (Table 3). Sociodemographic variables and habits of life presented no significant differences between the groups of "compromised" and "uncompromised" QoL.

All the variables that were significant $(P<0.10)$ entered into the final modeling (Table 4).

In the final model, the presences of pain in the dorsal region, in the hands, in the thighs and in the feet were maintained as independent predictive variables for neuropathic pain. After the Hosmer-Lemeshow statistics $\left(\chi^{2}=0.196\right.$; $\mathrm{P}$ $=0.995)$, it was able to correctly classify $68.6 \%$ of the individuals.

All these procedures were adopted in each of the domains of SF-36; however, the option was taken to present only the main findings by means of texts, due to the limit on tables and pages of the article.
In the analysis of impacts on the emotional aspects of QoL in patients with chronic pain, the final model maintained the variables neuropathic pain $(\mathrm{P}=0.028)$ and presence of pain in the neck $(\mathrm{P}=0.044)$ and thighs $(\mathrm{P}=0.034)$ as independent predictive variables for compromised QoL, with reference to emotional aspects. The model presented adjustment criteria that indicated its adjustment both by the traditional criteria $(\mathrm{P}<0.001)$, and in agreement with the Hosmer-Lemeshow statistics $\left(\chi^{2}=1.625 ; \mathrm{P}=0.654\right)$, it was able to correctly classify $61.8 \%$ of the individuals.

With regard to the physical aspects of the instrument, the final adjusted model maintained the variables smoking $(\mathrm{P}=0.041)$, pain in the dorsal region $(\mathrm{P}=0.018)$ and neuropathic pain $(\mathrm{P}=0.017)$ as independent predictors; that is to say, they diminished the individual's chance of being classified as having an uncompromised QoL, with reference to physical aspects. The model presented adjustment criteria that indicated its adjustment both by the traditional criteria $(\mathrm{P}<0.001)$, and in agreement with the Hosmer-Lemeshow statistics $\left(\chi^{2}=2.292 ; \mathrm{P}=0.807\right)$, it was able to correctly classify $65.4 \%$ of the individuals.

As regards the impact on social aspects, the final model maintained the variables pain in the hands, in the neck and neuropathic pain. The presence of these pains diminished the individual's chance of being classified as having an uncompromised QoL as regards social aspects. However, only the variable neuropathic pain was shown to be significant at the level of $5 \%$, the others presented $\mathrm{P}>0.05$, but contributed to adjustment of the model. The model presented adjustment criteria that indicated its adjustment both by the traditional criteria $(\mathrm{P}<0.001)$, and in agreement with the Hosmer-Lemeshow statistics $\left(\chi^{2}=0.185 ; \mathrm{P}=0.980\right)$, it was able to cor- 
Table 3. Multiple Logistic Regression Predictors of "Neuropathic Pain" in a Population Sample of a Health Unit, Salvador, Bahia, Brazil

\begin{tabular}{|c|c|c|c|c|c|c|}
\hline Variables & B & $\begin{array}{l}\text { Standard } \\
\text { error }\end{array}$ & Wald & df & $\mathbf{P}$ & Crude OR (IC 95\%) \\
\hline Pain in shoulders & 0.935 & 0.354 & 6.994 & 1 & 0.008 & $2.548(1.274-5.096)$ \\
\hline Constant & 0.163 & 0.173 & 0.894 & 1 & 0.344 & 1.177 \\
\hline Pain in dorsal region & 1.323 & 0.478 & 7.672 & 1 & 0.006 & $3.755(1.472-9.576)$ \\
\hline Constant & 0.217 & 0.161 & 1.834 & 1 & 0.176 & 1.243 \\
\hline Pain in arms & 1.070 & 0.485 & 4.870 & 1 & 0.027 & $2.917(1.127-7.547)$ \\
\hline Constant & 0.273 & 0.159 & 2.969 & 1 & 0.085 & 1.314 \\
\hline Pain in hands & 1.504 & 0.564 & 7.109 & 1 & 0.008 & $4.500(1.489-13.596)$ \\
\hline Constant & 0.245 & 0.157 & 2.427 & 1 & 0.119 & 1.278 \\
\hline Pain in thighs & 1.187 & 0.428 & 7.699 & 1 & 0.006 & $3.277(1.417-7.579)$ \\
\hline Constant & 0.199 & 0.164 & 1.485 & 1 & 0.223 & 1.221 \\
\hline Pain in knees & 0.718 & 0.304 & 5.580 & 1 & 0.018 & $2.050(1.130-3.719)$ \\
\hline Constant & 0.097 & 0.197 & 0.243 & 1 & 0.622 & 1.102 \\
\hline Pain in legs & 0.692 & 0.331 & 4.364 & 1 & 0.037 & $1.997(1.044-3.821)$ \\
\hline Constant & 0.202 & 0.177 & 1.306 & 1 & 0.253 & 1.224 \\
\hline Pain in feet & 1.625 & 0.421 & 14.924 & 1 & $<0.001$ & $5.076(2.226-11.575)$ \\
\hline Constant & 0.057 & 0.169 & 0.114 & 1 & 0.735 & 1.059 \\
\hline
\end{tabular}

rectly classify $64.4 \%$ of the individuals.

For the functional capacity domain, individuals between 31 and 60 years of age $(P=0.039)$ have less chance of being classified as having an uncompromised QoL, as regards functional capacity, and this was affected by the presence of neuropathic pain $(\mathrm{P}<0.001)$ and pain in the dorsal region $(\mathrm{P}$ $=0.030)$. The model presented adjustment criteria that indicated its adjustment both by the traditional criteria $(\mathrm{P}<$

Table 4. Multivariate Analysis Adjusted for Independent Predictors of Neuropathic Pain in the Population Sample of a Registered Health Unit, Salvador, Bahia, Brazil

\begin{tabular}{llllll}
\hline Variables & B & Standard error & Wald & P & Adjusted OR (IC 95\%) \\
\hline Pain in dorsal region & 1.355 & 0.503 & 7.261 & 0.007 & $3.879(1.447-10.395)$ \\
Pain in hands & 1.236 & 0.597 & 4.283 & 0.038 & $3.440(1.068-11.085)$ \\
Pain in thighs & 0.974 & 0.460 & 4.488 & 0.034 & $2.649(1.076-6.522)$ \\
Pain in feet & 1.378 & 0.442 & 9.730 & 0.002 & $3.969(1.669-9.437)$ \\
\multicolumn{1}{c}{ Constant } & -0.393 & 0.206 & 3.657 & 0.056 & 0.675 \\
\hline
\end{tabular}

$\chi^{2}=36.943 ; \mathrm{gl}=4 ; \mathrm{P}<0.001$. 
Table 5. Multiple Logistic Regression Predictors of the Total Score of SF-36 in a Population Sample of a Health Unit, Salvador, Bahia, Brazil

\begin{tabular}{lllllll}
\hline Variables & B & $\begin{array}{l}\text { Standard } \\
\text { error }\end{array}$ & Wald & df & $\mathbf{P}$ & Crude OR (IC 95\%) \\
\hline Severe pain & -0.785 & 0.358 & 4.797 & 1 & 0.029 & $0.456(0.226-0.921)$ \\
$\quad$ Constant & 0.241 & 0.201 & 1.433 & 1 & 0.231 & 1.273 \\
Pain in shoulders & -0.890 & 0.331 & 7.217 & 1 & 0.007 & $0.411(0.215-0.786)$ \\
$\quad$ Constant & 0.223 & 0.173 & 1.660 & 1 & 0.198 & 1.250 \\
Pain in dorsal region & -1.188 & 0.420 & 7.979 & 1 & 0.005 & $0.305(0.134-0.695)$ \\
$\quad$ Constant & 0.166 & 0.160 & 1.074 & 1 & 0.300 & 1.181 \\
Pain in arms & -0.716 & 0.421 & 2.890 & 1 & 0.089 & $0.489(0.214-1.116)$ \\
$\quad$ Constant & 0.074 & 0.157 & 0.222 & 1 & 0.637 & 1.077 \\
$\begin{array}{l}\text { DN4 score } \\
\text { (neuropathic pain) }\end{array}$ & -1.326 & 0.314 & 17.867 & 1 & $<0.001$ & $0.266(0.144-0.491)$ \\
$\quad$ Constant & 0.773 & 0.247 & 9.817 & 1 & 0.002 & 2.167 \\
\hline
\end{tabular}

$0.001)$, and in agreement with the Hosmer-Lemeshow statistics $\left(\chi^{2}=10.456 ; \mathrm{P}=0.234\right)$, it was able to correctly classify $67.5 \%$ of the individuals.

As regards the impact on the SF-36 domain of pain, after the adjusted analysis, the following variables of the raw analysis remained in the final model: time of pain between 5 and 10 years $(\mathrm{P}=0.05)$ and pain in the dorsal region $(\mathrm{P}$ $=0.015)$, being variables that reduced the QoL with reference to the aspect of pain. The model presented adjustment criteria that indicated its adjustment both by the traditional criteria $(\mathrm{P}<0.001)$, and in agreement with the Hosmer-Lemeshow statistics $\left(\chi^{2}=1.376 ; \mathrm{P}=0.967\right)$, it was able to correctly classify $64.4 \%$ of the individuals.

In the domain of general state of health, the final model maintained the variables intense pain $(\mathrm{P}<0.001)$ and type of neuropathy $(\mathrm{P}=0.003)$ as independent predictors; that is to say, variables that diminished the individual's chance of being classified as having an uncompromised QoL, with regard to the general state of health. The model presented adjustment criteria that indicated its adjustment both by the traditional criteria $(\mathrm{P}<0.001)$, and in agreement with the Hosmer-Lemeshow statistics $\left(\chi^{2}=4.901 ; \mathrm{P}=0.672\right)$, it was able to correctly classify $68.1 \%$ of the individuals.

In the domain of mental health, the final model maintained the variables intense pain $(\mathrm{P}=0.008)$, pain in the head/headache $(\mathrm{P}=0.002)$, pain in the neck $(\mathrm{P}=0.014)$ and the type of neuropathy $(\mathrm{P}=0.003)$ as independent predictors; that is to say, variables that diminished the individual's chance of being classified as having an uncompromised
QoL, with regard to the SF-36 domain of mental health. The model presented adjustment criteria that indicated its adjustment both by the traditional criteria $(\mathrm{P}<0.001)$, and in agreement with the Hosmer-Lemeshow statistics $\left(\chi^{2}=1.310 ; \mathrm{P}=\right.$ $0.995)$, it was able to correctly classify $68.6 \%$ of the individuals.

With regard to vitality, the final model maintained the variables time of pain exceeding 10 years $(P=0.018)$, and pain of the neuropathic type $(\mathrm{P}=0.002)$, as independent predictors; that is to say, variables that diminished the individual's chance of being classified as having an uncompromised QoL, with regard to the SF-36 domain of vitality. The model presented adjustment criteria that indicated its adjustment both by the traditional criteria $(\mathrm{P}<0.002)$, and in agreement with the Hosmer-Lemeshow statistics $\left(\chi^{2}=0.775 ; \mathrm{P}=0.942\right)$, it was able to correctly classify $61.8 \%$ of the individuals.

To assess the impact of a single isolated variable in "SF36 ", multiple logistic regression was performed, searching for the raw OR values, beyond the confidence intervals of $95 \%$.

When analyzing each variable in isolation, it was noted that at a level of significance lower than or equal to $10 \%$, having intense pain, in the shoulder, dorsal region, in the arms, of the neuropathic type $(\mathrm{P}<0.001)$, diminished the individual's chance of being classified as having an uncompromised QoL SF-36 (Table 5).

The final model adjusted in this method may be observed in Table 6.

The final model maintained the variables pain in the dor- 
Table 6. Adjusted Analysis of the Predictors of the Total Score of SF-36 in the Population Sample of a Registered Health Unit, Salvador, Bahia, Brazil

\begin{tabular}{|c|c|c|c|c|c|}
\hline Variables & B & $\begin{array}{l}\text { Standard } \\
\text { error }\end{array}$ & Wald & $\mathbf{P}$ & Adjusted OR (IC 95\%) \\
\hline Pain in dorsal region & -1.169 & 0.470 & 6.185 & 0.013 & $0.311(0.124-0.781)$ \\
\hline $\begin{array}{l}\text { Time of pain less than } 5 \\
\text { years }\end{array}$ & & & 5.119 & 0.077 & \\
\hline $\begin{array}{l}\text { Time of pain between } 5 \text { and } \\
10 \text { years }\end{array}$ & -0.403 & 0.375 & 1.152 & 0.283 & $0.668(0.320-1.395)$ \\
\hline $\begin{array}{l}\text { Time of pain exceeding } 10 \\
\text { years }\end{array}$ & 0.626 & 0.422 & 2.203 & 0.138 & $1.870(0.818-4.272)$ \\
\hline Without pain at the moment & & & 7.249 & 0.064 & \\
\hline Slight pain & -0.755 & 0.649 & 1.353 & 0.245 & $0.470(0.132-1.677)$ \\
\hline Moderate pain & -0.541 & 0.471 & 1.320 & 0.251 & $0.582(0.231-1.466)$ \\
\hline Severe pain & -1.048 & 0.401 & 6.814 & 0.009 & $0.351(0.160-0.770)$ \\
\hline DN4 score (neuropathic pain) & -1.227 & 0.333 & 13.563 & $<0.001$ & $0.293(0.153-0.563)$ \\
\hline Constant & 1.294 & 0.360 & 12.936 & 0.000 & 3.649 \\
\hline
\end{tabular}

$\chi^{2}=36.355 ; \mathrm{gl}=7 ; \mathrm{P}<0.001$.

sal region, intense pain and type of neuropathy, as predictive variables for compromised QoL. The model presented adjustment criteria that indicated its adjustment both by the traditional criteria and in agreement with the Hosmer-Lemeshow statistics $\left(\chi^{2}=9.186 ; \mathrm{P}=0.327\right)$, it was able to correctly classify $64.9 \%$ of the individuals.

\section{Discussion}

In this study, it was observed that neuropathic pain caused the greatest repercussions in all the domains evaluated, which reinforces the importance of identifying neuropathic pain at population level.

In the studied community, women who were single, nonwhite, non-consumers of alcohol and nonsmokers made up the sociodemographic profile of the persons who suffer from chronic pain. Similar results have also been found in the literature [14-17].

In the raw descriptive analysis, it was observed that the sites most affected were the lumbar spine, knees and head; however, none of these sites was an independent predictor of neuropathic pain. The lumbar region has been the one most affected in various epidemiologic studies that evaluated the presence of chronic pain $[18,19]$. Therefore, it was possible to identify that the lumber region, lower and upper limbs were the regions that caused the greatest repercussions on the loss of QoL when associated with neuropathic pain. It has been verified that neuropathic pain generally affects more than one site, and in the majority of cases, involves the region of the back and lower limbs [15, 20].

The participants presented moderate to intense pain, which is in agreement with that which has been observed in population studies when the prevalent type of pain is neuropathic $[14,21]$. This datum points out the need for analgesic support in the FHUs, in addition to preventive actions. The intense pain was also strongly associated with neuropathic pain, and with the worst QoL indices in the multivariate analysis. In spite of the intense pain, the majority of the individuals declared that their general state of health was good. Phenomena such as religion, resilience and greater capacity to face up to pain in populations with a low socioeconomic level may have influenced this perception of the general state of health [20].

Individuals with neuropathic pain had their QoL reduced in all the domains. This finding was also confirmed, particu- 
larly in the physical and mental aspects [12]. The most compromised domains in the evaluation of QoL were the physical aspect, pain and the emotional aspect. These data confirm the findings of a study conducted by other researchers with individuals who presented the same domains, in the same order of compromise [22, 23]. When individuals are affected by chronic disease, it is not only the pathologic factor that influences the situation, because there are changes in their lives related to physical discomfort, losses of a personal, financial and social order [22]. It has been shown that the repercussion of chronic pain on the QoL is more related to neuropathic pain than to intensity or duration [20].

As regards the emotional aspects, the low scores in neuropathic pain have been confirmed by population studies [20]. In other studies, it has been observed that for the physical aspects, greater relationship has been found with smoking and pain in the region of the back [15]. Whereas for the domain of social aspects, our data point to the neck and upper limbs being more affected, but no similar data were found in the different studies. One supposes that the loss of functionality of the upper limbs related to the presence of neuropathic pain would impede those who are affected from continued participation in intense work and social activity.

When we sought variables that predicted compromised QoL in the individual with chronic pain, we found that having intense pain of the neuropathic type in the dorsal region reduced the individual's chance of having a high QoL. All the QoL domains are harmed to a greater extent in individuals who report chronic pain with neuropathic characteristics [20]. Individuals that had chronic pain with neuropathic characteristics presented low scores in all the domains when compared with the scores presented by patients with other serious somatic diseases, as in the case of cardiopathies [14, 23].

\section{Conclusions}

Cross-sectional studies have limitations inherent to the mod$\mathrm{el}$, and this is why the results must take into consideration the difficulty of establishing causal relationships.

With this epidemiologic study, it was possible to dimension the impact of pain of the neuropathic type in a community with a low socioeconomic condition with an important reduction in the QoL of those in pain. These findings point out the need for pain prevention. In this low income population, it was observed that chronic pain mainly affected the regions of the knee and lumbar spine, presented high intensity, long duration and impact on different aspects of the QoL, irrespective of the sites affected. Women are affected to a greater extent, and neuropathic pain causes greater impact on the QoL than nociceptive pain does. It was therefore concluded that intense pain in the dorsal region and of the neuropathic type are independent predictors for greater compromise of QoL.

\section{Competing Interests}

The authors declare that expenditures for research were made by researchers.

\section{Author Contributions}

ASMV: conception and design, acquisition of data, analysis and interpretation of data; drafting the manuscript and revising it critically for important intellectual content; final approval of the version to be published. AFB: contribuitions to concepting and design; revising it critically for important intellectual content; final approval of the version to be published. LM/KSS/SCAG/FMAL: acquisition of data, analysis and interpretation of data; drafting the manuscript; final approval of the version to be published. IS: analysis and interpretation of data; drafting the manuscript; final approval of the version to be published. KNS: concepting and design; revising it critically for important intellectual content; final approval of the version to be published.

\section{References}

1. Castro M, Kraychete D, Daltro C, Lopes J, Menezes R, Oliveira I. Comorbid anxiety and depression disorders in patients with chronic pain. Arq Neuropsiquiatr. 2009;67(4):982-985.

2. Ruviaro L, Filippin L. Prevalencia de dor cronica em uma unidade Basica de Saude de cidade de Medio Porte. Revista Dor. 2012;128-131.

3. Crombie I. The potencial of Epidemiology. In: Crombie IK, Croft PR, Linton SJ, LeResche L, Von Korff M, editors. Epidemiology of pain: a report of the task force on Epidemiology. IASP Press. 1999;1-5.

4. Toth C, Lander J, Wiebe S. The prevalence and impact of chronic pain with neuropathic pain symptoms in the general population. Pain Med. 2009;10(5):918-929.

5. Kraychete D, Gozzani J, Kraychete A. Dor neuropaticaaspectos neuroquimicos. Revista Brasileira de Anestesiologia. 2008;58(5):492-505.

6. Garcia D, Pimenta C, Cruz D. Validacao do inventario de atitudes frente a dor cronica-Profissionais. Revista da Escola de Enfermagem da USP. 2007;41(4):636-644.

7. Escorel S, Giovanella M, Senna M. O Programa de Saude da Familia e a construcao de um novo modelo para a atencao basica no Brasil. Revista Panamericana de Salud Publica. 2007;21(2):164-176.

8. Sa KN, Baptista AF, Matos MA, Lessa I. Chronic pain and gender in Salvador population, Brazil. Pain. 2008;139(3):498-506.

9. Paiva D, Bersusa A, Escuder M. Avaliacao da assistencia ao paciente com diabetes e/ou hipertensao pelo Pro- 
grama de Saude da Família do municipio de Francisco Morato, Sao Paulo, Brasil. Caderno de Saude Publica. 2006;22(2):377-385.

10. Pedrosa D, Pelegrin A, Siqueira H, Silva T, Colhado O, Sousa F. Avaliacao da qualidade de vida em clientes com dor cronica isquemica. Revista Latino-Americana de Enfermagem. 2011;19(1):67-72.

11. Seidl E, Zannon C. Qualidade de vida e saude: Aspectos conceituais e metodologicos. Caderno de Saude Publica. 2004;20(2):580-588.

12. Vall J, Braga V, Almeida P. Estudo da qualidade de vida em pessoas com lesao medular traumatica. Arquivos de Neuropsiquiatria. 2006;64(2-B):451-455.

13. Pimenta F, Simil F, Torres H, Amaral C, Rezende C, Coelho T, Rezende N. Avaliacao da qualidade de vida de aposentados com a utilizacao do questionario SF-36. Revista da Associacao Medica Brasileira. 2008;54(1):5560.

14. Bouhassira D, Lanteri-Minet M, Attal N, Laurent B, Touboul C. Prevalence of chronic pain with neuropathic characteristics in the general population. Pain. 2008;136(3):380-387.

15. Harifi G, Amine M, Ait Ouazar M, Boujemaoui A, Ouilki I, Rekkab I, Belkhou A, et al. Prevalence of chronic pain with neuropathic characteristics in the Moroccan general population: a national survey. Pain Med. 2013;14(2):287-292.

16. Schestatsky P. Definicao, Diagnostico e Tratamento da
Dor Neuropatica. Revista do Hospital de Clinicas de Porto Alegre. 2008;28(3):177-187..

17. Torrance N, Smith BH, Bennett MI, Lee AJ. The epidemiology of chronic pain of predominantly neuropathic origin. Results from a general population survey. J Pain. 2006;7(4):281-289.

18. Montini F, Neman F. Prevalencia e avaliacao da dor cronica nos cadastrados da Unidade Basica de Saude Jardim Palmira, Guarulhos/SP. Science in Health. 2012;3(2):75-86.

19. Sa K, Baptista A, Matos M, Lessa I. Prevalencia de dor cronica e fatores associados na populacao de Salvador, Bahia. Revista de Saude Publica. 2009;43(4):622-630.

20. Attal N, Lanteri-Minet M, Laurent B, Fermanian J, Bouhassira D. The specific disease burden of neuropathic pain: results of a French nationwide survey. Pain. 2011;152(12):2836-2843.

21. Ferreira K, Siqueira R, Texeira J. Caracteristicas demograficas, da dor e do tratamento dos pacientes atendidos em Centro Multidisciplinar de Dor. Caderno de Saude Coletiva. 2008;16(3):449-470.

22. Brasil V, Zatta L, Cordeiro J. Qualidade de vida de portadores de dor cronica em tratamento com acupuntura. Revista Eletronica de Enfermagem. 2008;10(2):383-394.

23. Smith BH, Torrance N, Bennett MI, Lee AJ. Health and quality of life associated with chronic pain of predominantly neuropathic origin in the community. Clin J Pain. 2007;23(2):143-149. 